\title{
Editorial
}

\section{Health Problems of Elderly People in Bangladesh}

\author{
Islam $\mathrm{MA}^{1}$, Rahman $\mathrm{MF}^{2}$
}

The population of Bangladesh is 'greying' quite fast and posing an important issue in the field of public health. The average life expectancy of Bangladeshi people rises to 72.49 years. Life expectancy for women is now slightly higher than that of male. The Bangladeshis average life expectancy had surpassed the world average ${ }^{1}$. Seven percent of total population of our country are above 60 years ${ }^{2}$. With the increasing load of elderly, many additional issues are adding in the healthcare service and delivery system throughout the world including Bangladesh. These older citizens either our respected seniors or parents and once they were head of the family, society and in many cases coloured their lives in every sphere of life.

While considering the elderly people healthcare services, a distinction must be made between functional limitations and disabilities. Functional limitations are restrictions in performing fundamental physical activities like- difficulty in ambulating and climbing stairs. On the other hand, disabilities are the functional limitation placed on social context like loss of self-dependency.

People in America today can expect to live longer than ever before. Once you make it to 65 , the data suggest that you can live another 19.3 years, on average, according to the Centers for Disease Control and Prevention (CDC). Making healthy lifestyle choices, like quitting smoking and losing weight can help you avoid senior health risks though you also need to be physically active and eat a healthy diet ${ }^{3}$.

Common health problems that occur in elderly in Bangladesh are Cardiovascular disease including Hypertension, Stroke, Angina, Myocardial infarction or Heart attack, Diabetes mellitus and its complications, Cataract, Arthritis, Osteoporosis, Skeletal deformity, Obesity, Enlarged prostate in men, Sleep disturbance, Changes in behaviour, Dementia ${ }^{4}$. Cancer is another important disease. Elderly people suffer from cancer like prostate, lung, stomach, colon, breast and cervix of uterus. Arthritis affects $50 \%$ of people over 65 years and can lead to pain and lower quality of life for some of them.
According to CDC, Heart disease remains the leding killer of adults over 65, cancer is the second and Chronic Obstructive Pulmonary Disease (COPD) is the third most common cause of death among people over 65 years ${ }^{3}$.

A cross sectional study carried out by house to house survey of all people aged over 60 years in an urban slum and a village in India found that use of tobacco is very high $58.9 \%$. Visual impairment was the most common handicap in that study $83.29 \%$. Uncorrected hearing impairment was also common. A large portion had dental problem. Almost half of the population had depression ${ }^{5}$.

Prevalence of cognitive impairment among elderly people is about $22.4 \%$ found in a Malaysian study ${ }^{6}$. The most common mental and neurological disorder in this age group are Dementia and Depression which affect approximately $5 \%$ and $7 \%$ of world's older people respectively?

This issue of JAFMC has included a study relating health problems of elderly patients attending Combined Military Hospital, Dhaka where it is found that majority of elderly patients had Diabetes mellitus $(21.1 \%)$ followed by Rheumatoid arthritis (17.6\%), Asthma (12.5\%), Cataract (11.2\%), ENT problem (6.6\%), Malignancy (5.9\%) and Benign enlargement of prostate $(5.3 \%)$.

Elderly people in lower and lower middle socio-economic class suffers from financial crisis when they are in need of money for treatment. In a study in Dhaka district, only $14 \%$ of elderly had health insurance coverage ${ }^{8}$.

It is a matter of great hope and aspiration that present Govt of Prime Minister Sheikh Hasina launched old age allowance programme for the elderly in Bangladesh. Under this programme about $33,000,00$ people are getting TK 500 in each month estimating total cost of 2,100 crores each year. This is not sufficient for an old individual but it is a boost up and hopes by the Govt for the older people.

1. Brig Gen Md Azizul Islam, MBBS, FCPS (Psych), FRCP (UK), FACP (USA), Professor \& Head, Department of Psychiatry, Armed Forces Medical College, Dhaka Cantonment 2. Maj Gen Md Fashiur Rahman, ndc, MBBS, MPH, LLB, FCGP, MBA, MSS, PhD Fellow, Commandant, Armed Forces Medical College, Dhaka Cantonment. 
Awareness among older people should be created for health insurance, for depositing money for old age medical crisis and for regular health check-up for early detection and management of their problems.

While sick, an elderly patient should be taken to physician or hospital by the younger loved ones. It can boost the morale of the sick person and he or she may feel the smile of success in life. Our new generation should be responsive, informed and attentive about their duties and responsibilities towards the elder who are actually our parents and senior citizen. Taking care of elder people is our ethical duty and responsibility.

There is a need to have geriatric ward having specialized professionals with Psychiatric and medical social workers along with subsidized health care services.

\section{References}

1. Bangladesh life expectancy up: BBS. BDNews24.com, 25 April 2017. Available at https://bdnews24.com/bangladesh/2017/04/25/ bangladesh-life-expectancy-up-bbs

2. Demographics of Bangladesh. Available at https://en.wikipedia. org/wiki/Demographics_of_Bangladesh
3. Vann MR. The 15 Most Common Health Concerns for seniors. Cited on 8 January 2016. Available at https://www.everydayhealth.com/news/ most-common-health-concerns-seniors/

4. Shahidullah M. Common health problems in elderly people. The Independent, 9 October, 2017. Available at http://www.theindependentbd. com/arcprint/details/117906/2017-10-09

5. Thakur RP, Banerjee A and Nikumb VB. Health Problems among the Elderly: A Cross-Sectional Study. Ann Med Health Sci Res 2013; 3(1):19-25.

6. Sidik SM, Rampal L and Afifi M. Physical and Mental Health Problems of the Elderly in a Rural Community of Sepang, Selangor. Malays $\mathrm{J}$ Med Sci 2004; 11(1):52-9.

7. Mental health of older adults. World health organization, News letter, 12 Dec 2017. Available at http://www.who.int/news-room/factsheets/detail/mental-health-of-older-adults

8. Hosain GM, Begum A. Health needs and health status of the elderly in rural Bangladesh. Asia Pac J Public Health 2003; 15(1):3-9. 